\title{
A RETROSPECTIVE ORAL HISTORY OF COMPUTER SIMULATION: PROGRESS REPORT
}

\author{
Richard E. Nance \\ Department of Computer Science \\ Virginia Polytechnic Institute \& State University \\ Blacksburg, VA 24061, USA
}

\author{
Robert G. Sargent \\ Dept. Electrical Engineering \& Computer Science \\ Syracuse University \\ Syracuse, NY 13244, USA
}

\author{
James R. Wilson \\ Edward P. Fitts Department of \\ Industrial \& Systems Engineering \\ North Carolina State University \\ Raleigh, NC 27695, USA
}

\begin{abstract}
The primary objective of the project titled "A Retrospective Oral History of Computer Simulation" is to document the emergence of computer simulation since World War II. We seek to capture the early history of the field through digital videos of interviews with the pioneers whose seminal contributions have had long-lasting impacts on simulation practice and theory. This project involves the following activities: (a) identifying those pioneers who are to participate in the project; (b) making the logistical arrangements necessary to produce high-quality digital-video recordings of structured interviews with those pioneers; and (c) carrying out the interviews, editing the recordings, and posting those recordings in a universally accessible permanent digital repository. The digital videos produced by this project will be made freely available on the Web site of the Simulation Archive hosted by the North Carolina State University Libraries. We discuss progress to date and future plans for the project.
\end{abstract}

\section{INTRODUCTION AND BACKGROUND}

\subsection{The Historical Roots of Computer Simulation}

The history of simulation precedes that of the digital computer by over 200 years, but the advent of the general-purpose electronic computer transformed Monte Carlo simulation from a brute-force, humanintensive, overly demanding problem-solving technique to one that was effective, efficient, broadly applicable, and extremely popular; see Burks and Burks (1981), Cooper (1989), Hammersley and Handscomb (1964), Pearson (1990), Todhunter (1965), and Goldstine (1972). The application of Monte Carlo in the repetition of statistically independent trials required the discovery of a method for producing uncertainty in computational machines that were inherently deterministic because of a finite word-length and a finite population of numerical representations. The work of Ulam, Metropolis, and von Neumann at Los Alamos using the middle-of-the-square (MOS) technique for producing pseudorandom numbers seemed a sufficient answer to this question (Cooper 1989, Metropolis 1987). However, the lack of a theoretical basis for MOS and the failings frequently encountered in experimental use led to recognition of the need for a better method of random number generation (RNG). In 1948 Derrick Lehmer addressed this need by formulating two methods for producing linear congruential RNGs (Lehmer 1951). Expansion in the size 
of internal memory in the early- to mid-1950s extended the period of linear congruential RNGs, making their applicability more apparent in their use in Monte Carlo experiments (Knuth 1998).

A different group of engineers and scientists envisioned applications of the experimental technique in areas where time-sequenced events governed the representation of state transitioning in manufacturing systems, typically described as job shop scheduling. A critical player in this domain was Harry Markowitz, who held positions at General Electric and the RAND Corporation, while seeking to develop a generally descriptive approach to representing job shop scheduling systems. The primary obstacle was the incorporation of time and state characterization in an efficient computational algorithm. Markowitz entered into a working relationship with Alan Rowe, who later based his doctoral dissertation at UCLA on a general simulation model of job shop scheduling enterprises. In the attempt at GE to apply their research experience, Rowe and Markowitz discovered the daunting challenge of generalizing a simulation model. Markowitz returned to RAND to pursue his goal of developing a general modeling technique: a simulation programming language that would materialize in SIMSCRIPT; see Kiviat, Villanueva, and Markowitz (1968) and Markowitz (1979). Based on similar experiences in using simulation to solve problems in job shop scheduling at Cornell University, Richard Conway, B. M. Johnson, and William Maxwell formulated the central problems of discrete-event simulation in two seminal papers, Conway (1963) and Conway, Johnson and Maxwell (1959). Many of the problems, and the proposed solution methods, detailed in these papers remain active areas of research and development today.

In the early to mid-1960s, the RAND Corporation was the focal point of many fundamental contributions to the field of computer simulation. Working with Harry Markowitz, Philip Kiviat made major contributions to the development and implementation of SIMSCRIPT II (Kiviat, Villanueva, and Markowitz 1968). Richard Conway and William Maxwell were also frequent visitors to RAND. During this period, George Fishman began his groundbreaking work on statistical methodology for simulation design and analysis. The impetus for this work arose from Fishman's extensive interactions with Kiviat, Pritsker, and others at RAND; see p. 30 of Alexopoulos, Goldsman, and Wilson (2009). Concurrently with the SIMSCRIPT effort, the work of K. D. Tocher and D. G. Owen in the United Kingdom produced the first simulator: the General Simulation Program (GSP) - a set of routines that were common to the application of simulation (Tocher and Owen 1960). At Bell Laboratories and IBM, Geoffrey Gordon was creating the General Purpose Simulation System (GPSS), which had several predecessor names using the same or a similar acronym (Gordon 1981). During the period 1964-1969, Kiviat also worked on the development of GASP II with Alan Pritsker at Arizona State University (Pritsker and Kiviat 1969). The work of Dahl and Nygaard at the Royal Norwegian Computing Center in the design of SIMULA and the subsequent production of SIMULA 67, the first object-oriented programming language, introduced the powerful class concept and a process interaction framework that completed the early conceptual frameworks distinguishing among the simulation programming languages: (i) event scheduling (SIMSCRIPT); (ii) three-phase (GSP); (iii) transaction processing (GPSS); and (iv) process interaction (SIMULA). See Nygaard and Dahl (1981) for a detail account of this seminal work.

\subsection{Previous Efforts to Document and Archive the Early History of Computer Simulation}

Some preliminary efforts have been made to document the early history of computer simulation as described briefly above. Special emphasis should be given to the following: (a) the archival journal article by Nance (1996) on the history of discrete-event simulation programming languages; and (b) the archival journal article by Nance and Sargent (2002) on the history of computer simulation up to 2002, the fiftieth anniversary of Operations Research, one of the flagship publications of the Institute for Operations Research and the Management Sciences (INFORMS). Unique in the simulation literature, Nance (1996) provides key insights into some of the factors driving progress of the field of simulation since its inception by surveying the development of thirty major simulation programming languages over the period 1955-1986. For the special fiftieth-anniversary issue of Operations Research, Nance and Sargent (2002) explore the synergy between the fields of computer science, operations research and computer simulation 
that has stimulated much of the dramatic growth and development of both fields over the period 19522002.

Coedited by David Goldsman (Georgia Tech) and James R. Wilson, the March 2001 issue of IIE Transactions honored Alan Pritsker on the occasion of his retirement. The editors coauthored the lead article on Pritsker's career (Wilson and Goldsman 2001) based on their extensive conversations with Pritsker during the last two years of his life. More recently, Christos Alexopoulos (Georgia Tech), Goldsman, and Wilson coedited the book titled Advancing the Frontiers of Simulation: A Festschrift in Honor of George Samuel Fishman (Alexopoulos, Goldsman, and Wilson 2009). In the lead article of that book, the editors surveyed Fishman's professional career; and the second article is the transcript of a fourhour interview with Fishman conducted during the period October 25-26, 2007.

In parallel with these efforts to document the early history of simulation, a larger-scale effort has been undertaken to archive this history systematically. In the late 1990s, Robert G. Sargent conceived the idea of a Simulation Archive that would be housed in a major university library as the main repository for the books, papers, and recorded interviews of the pioneers in the field of computer simulation. The Simulation Archive was established in 1998 at the North Carolina State University (NCSU) Libraries with the assistance of James R. Wilson,

\section{http://www.lib.ncsu.edu/specialcollections/simulation/ ;}

and an endowment to support this Archive was established in 2007 by Robert G. Sargent with a substantial contribution. The goal is to establish the archive as the premier source for researchers interested in the history and development of the field of simulation. The Simulation Archive is part of the Special Collections Research Center of the NCSU Libraries and receives exceptional support from the administration of the Libraries, including Dr. Susan Nutter, Vice Provost and Director of Libraries. There is an Advisory Committee (consisting of Richard E. Nance, Robert G. Sargent, and James R. Wilson) that works with the Library on management and advancement of the Simulation Archive. Several individuals have donated materials to the Archive and more have committed to donate in the future. Numerous groups and individuals have made financial contributions to the Simulation Archive Endowment, including the following professional organizations: the INFORMS Simulation Society (I-Sim), the Association for Computing Machinery/Special Interest Group on Simulation (ACM/SIGSIM), the American Statistical Association (ASA); the Department of Information Systems and Computing at Brunel University (UK); and the Edward P. Fitts Department of Industrial and Systems Engineering at NCSU. To date, the total amount donated to the endowment exceeds $\$ 40,000$.

To promote awareness of the activities of the Simulation Archive among the members of the international simulation community, Nance, Goldsman, and Wilson have given two invited ninety-minute presentations on the history of simulation from 1777 to 1982; see Goldsman, Nance and Wilson (2009, 2010). See also Wilson (2011).

\section{SUMMARY OF THE CURRENT PROJECT}

The project titled "A Retrospective Oral History of Computer Simulation" is jointly sponsored by the National Science Foundation and the Simulation Archive of the North Carolina State University Libraries. The primary objective of the project is to document the emergence of the field of computer simulation since World War II. Our approach is to capture the early history of the field by producing digital videos of interviews with the pioneers of the field whose seminal contributions have had long-lasting impacts on theory and practice, not only in computer simulation but also in the following disciplines: computer science; industrial, manufacturing, and systems engineering; and operations research and the management sciences. This project involves the following activities:

- Identifying those pioneers whose health enables them to participate in the project;

- making the logistical arrangements necessary to produce high-quality digital-video recordings of structured interviews with those pioneers; and 
- carrying out the interviews, editing the recordings, and posting those recordings in a universally accessible permanent digital repository. Another key project objective is to provide a template that can be used as an effective guide to performing similar projects for other disciplines, and then documenting the lessons learned from those projects.

The digital videos produced by this project will be made freely available on the Web site of the Simulation Archive hosted by the North Carolina State University Libraries; and the availability of the videos will be widely publicized in the international simulation community and in the broader professional communities that sponsor and participate in the Winter Simulation Conference, including relevant professional societies for women and underrepresented minorities. Faculty members who teach simulation will be encouraged to disseminate these videos to their students and to use the videos in their courses. These videos can also be used effectively in courses on the history of science and technology and in courses on ethnic and gender studies.

So far the following individuals have been interviewed: James O. Henriksen (Wolverine Software); Philip Kiviat (Guerra-Kiviat Inc.); Donald E. Knuth (Stanford University); Harry M. Markowitz (University of California, San Diego and Harry Markowitz Company); Richard E. Nance (ORCA Computer and Virginia Tech); Julian Reitman (Retired); Robert G. Sargent (Syracuse University); Thomas J. Schriber (The University of Michigan); and James R. Wilson (NC State University). Currently plans are being made to expand the list of interviewees over the next several months. The oral presentation of this paper will provide a more detailed summary of the work completed so far and the work planned in the near future.

\section{ACKNOWLEDGMENTS}

The work reported in this article is supported by NSF RAPID Project 1150107 and by the Simulation Archive of the North Carolina State University Libraries.

\section{REFERENCES}

Alexopoulos, C., D. Goldsman, and J. R. Wilson, eds. 2009. Advancing the Frontiers of Simulation: A Festschrift in Honor of George Samuel Fishman, 329+xiv pp. New York: Springer-Verlag.

Burks, A. W., and A. R. Burks. 1981. "The ENIAC: First General-Purpose Electronic Computer." Annals of the History of Computing 3 (4): 310-389.

Conway, R. W. 1963. "Some Tactical Problems in Digital Simulation." Management Science 10 (1): $47-61$.

Conway, R. W., B. M. Johnson, and W. L. Maxwell. 1959. "Some Problems of Digital Systems Simulation." Management Science 6 (1): 92-110.

Cooper, N. G., ed. 1989. From Cardinals to Chaos: Reflections on the Life and Legacy of Stanislaw Ulam. New York: Cambridge University Press.

Goldsman, D., R. E. Nance, and J. R. Wilson. 2009. “A Brief History of Simulation.” In Proceedings of the 2009 Winter Simulation Conference, edited by M. D. Rossetti, R. R. Hill, B. Johansson, A. Dunkin, and R. G. Ingalls, 310-313. Piscataway, New Jersey: Institute of Electrical and Electronics Engineers. http://www.informs-sim.org/wsc09papers/028.pdf [accessed August 13, 2013]. The slides for the oral presentation of this paper are available via http://www.ise.ncsu.edu/jwilson/files/simhist.pdf [accessed August 13, 2013].

Goldsman, D. G., R. E. Nance, and J. R. Wilson. 2010. "A Brief History of Simulation Revisited." In Proceeding of the 2010 Winter Simulation Conference, edited by B. Johansson, S. Jain, J. MontoyaTorres, J. Hugan, and E. Yücesan, 567-574. Piscataway, New Jersey: Institute of Electrical and Electronic Engineers, Inc. http://www.informs-sim.org/wsc10papers/051.pdf [accessed July 15, 2013]. The slides for the oral presentation of this paper are available via http://www.ise.ncsu.edu/jwilson /files/wsc10simhist.pdf [August 13, 2013]. 
Goldstine, H. H. 1972. The Computer from Pascal to von Neumann. Princeton, New Jersey: Princeton University Press.

Gordon, G. 1981. "The Development of the General Purpose Simulation System." In History of Programming Languages, edited by R. L. Wexelblatt, 403-437. New York: Academic Press

Hammersley, J. M., and D. C. Handscomb. 1964. Monte Carlo Methods. London: Chapman and Hall

Hollocks, B. W. 2008. "Intelligence, Innovation and Integrity-KD Tocher and the Dawn of Simulation. Journal of Simulation 2 (3): 128-137.

Kiviat, P. J., V. Villanueva, and H. M. Markowitz. 1968. The SIMSCRIPT II Programming Language. RAND Memorandum R-460-PR. Santa Monica, California: The RAND Corporation. http://www.rand.org/content/dam/rand/pubs/reports/2008/R460.pdf [accessed August 13, 2013].

Knuth, D. E. 1998. The Art of Computer Programming, Volume 2: Seminumerical Algorithms. 3rd ed. Reading, Massachusetts: Addison-Wesley.

Lehmer, D. H. 1951. "Mathematical Methods in Large-Scale Computing Units." Annals of the Computation Laboratory of Harvard University 26:141-146.

Markowitz, H. M. 1979. "SIMSCRIPT: Past, Present, and Some Thoughts about the Future." In Current Issues in Computer Simulation, edited by N. R. Adam and A. Dogramaci, 27-60. New York: Academic Press.

Metropolis, N. 1987. "Beginning of the Monte Carlo Method." Los Alamos Science Special Issue: 125130. http://library.lanl.gov/cgi-bin/getfile?00326866.pdf [accessed August 13, 2013].

Nance, R. E. 1996. "A History of Discrete Event Simulation Programming Languages." In History of Programming Languages - II, edited by T. J. Bergin and R. J. Gibson, 369-427. Reading, Massachusetts: ACM Press and Addison-Wesley Publishing Company.

Nance, R. E., and R. G. Sargent. 2002. "Perspectives on the Evolution of Simulation." Operations Research 50 (1, Special $50^{\text {th }}$ Anniversary Issue): 161-172

Nygaard, K., and O.-J. Dahl. 1981. "The Development of the SIMULA Languages." In History of Programming Languages, edited by R. L. Wexelblatt, 439-493. New York: Academic Press.

Pearson, E. S. 1990. 'Student': A Statistical Biography of William Sealy Gosset. Based on writings by E. S. Pearson. Edited and augmented by R. L. Plackett with the assistance of G. A. Barnard. Oxford: Clarendon Press and New York: Oxford University Press.

Pritsker, A. A. B., and P. J. Kiviat. 1969. Simulation with GASP II: A FORTRAN Based Simulation Language. Englewood Cliffs, New Jersey: Prentice-Hall, Inc.

Tocher, K. D., and D. G. Owen. 1960. "The Automatic Programming of Simulations." In Proceedings of the Second International Conference on Operational Research, edited by J. Banbury and J. Maitland, 50-68. London: The English Universities Press Ltd.

Todhunter, I. (1865) 1965. A History of the Mathematical Theory of Probability from the Time of Pascal to That of Laplace. Cambridge: Cambridge University Press. Reprint, New York: Chelsea Publishing Co.

Wilson, J. R., and D. Goldsman. 2001. "Alan Pritsker's Multifaceted Career: Theory, Practice, Education, Entrepreneurship, and Service." IIE Transactions 33 (3, Special Issue of Operations Engineering Honoring Alan Pritsker): 139-147.

Wilson, J. R. 2011. "Advances in Simulation: The Interplay of Inspiration, Intuition, Abstraction, and Experimentation." "Titans of Simulation" Plenary Address, 2011 Winter Simulation Conference, Phoenix, AZ, December 14, 2011. The slides for this presentation are available via http://www.ise.ncsu.edu/jwilson/wsc11tos.pdf [accessed August 13, 2013]. 
Nance, Sargent, and Wilson

\section{AUTHOR BIOGRAPHIES}

RICHARD E. NANCE is an Emeritus Professor of Computer Science at Virginia Tech. He received B.S. and M.S. degrees from North Carolina State University in 1962 and 1966, and the Ph.D. degree from Purdue University in 1968. He has served on the faculties of Southern Methodist University and Virginia Tech, where he was Department Head of Computer Science, 1973-1979. Dr. Nance held research appointments at the Naval Surface Weapons Center (1979-1980) and at the Imperial College of Science and Technology (UK). Within ACM, he has chaired two special interest groups: Information Retrieval (SIGIR), 1970-1971, and Simulation (SIGSIM), 1983-1985. He is the author of over 150 papers on discrete event simulation, performance modeling and evaluation, computer networks, and software engineering. Dr. Nance has held several editorial positions and was the founding Editor-in-Chief of the ACM Transactions on Modeling and Computer Simulation, 1990-1995. He served as Program Chair for the 1990 Winter Simulation Conference. Dr. Nance has received several awards for his editorial and professional contributions, most recently the Lifetime Professional Achievement Award from the INFORMS Simulation Society. He was named an ACM Fellow (1996) and an INFORMS Fellow (2008). In 2006 he was designated by the faculty as a Distinguished Alumnus of the Edward P. Fitts Department of Industrial and Systems Engineering, North Carolina State University. He is a member of Sigma Xi, Alpha Pi Mu, Upsilon Pi Epsilon, ACM, and INFORMS. His e-mail address is nance@vt.edu.

ROBERT G. SARGENT is a Professor Emeritus of Syracuse University. He received his education at The University of Michigan. Dr. Sargent has served his profession in numerous ways including being the General Chair of the 1977 Winter Simulation Conference, serving on the WSC Board of Directors for ten years and chairing the Board for two years, being a Department Editor for the Communications of the $A C M$, holding the Presidency and other offices of what is now the INFORMS Simulation Society, and serving as Founding President of the WSC Foundation. He has received several awards and honors for his professional contributions including the INFORMS Simulation Society's Lifetime Professional Achievement Award and also their Distinguished Service Award, a WSC 40th anniversary landmark paper award, the WSC Wilson Award, ACM SIGSIM Distinguished Contributions Award, service awards from ACM and IIE, and becoming a Fellow of INFORMS. His current research interests include the methodology areas of modeling and of discrete event simulation, model validation, and performance evaluation. Professor Sargent has published extensively and is listed in Who's Who in America and in Who's Who in the World. His e-mail is rsargent@syr.edu.

JAMES R. WILSON is a professor in the Edward P. Fitts Department of Industrial and Systems Engineering at North Carolina State University. Dr. Wilson's current research interests are focused on probabilistic and statistical issues in the design and analysis of simulation experiments. Dr. Wilson has held the following editorial positions: departmental editor of Management Science (1988-1996); area editor of ACM Transactions on Modeling and Computer Simulation (1997-2002); guest editor of a special issue of IIE Transactions honoring Alan Pritsker (1999-2001); and Editor-in-Chief of ACM Transactions on Modeling and Computer Simulation (2004-2010). He served The Institute of Management Sciences College on Simulation as secretary-treasurer (1984-1986); vice president (1986-1988); and president (1988-1990). As a participant in the Winter Simulation Conference (WSC), he served as proceedings editor (1986); associate program chair (1991); and program chair (1992). As a member of the WSC Board of Directors corepresenting the INFORMS Simulation Society during the period 1997-2004, he has served as secretary (2001); vice chair (2002); and chair (2003). As a trustee of the WSC Foundation during the period 2006-2009, he served as secretary (2006), vice-president (2007), and president (2008). He is a member of ACM, ASA, and SCS; and he is a Fellow of IIE and INFORMS. In 2013 he received the David F. Baker Distinguished Research Award from the Institute of Industrial Engineers. His e-mail address is jwilson@ncsu.edu, and his web page is www.ise.ncsu.edu/jwilson. 